Herz 2014 · 39:297-298

DOI 10.1007/s00059-014-4084-3

Published online: 27. März 2014

(c) Urban \& Vogel 2014

D. Tschöpe ${ }^{1} \cdot$ R. Dörr ${ }^{2} \cdot$ D. Müller-Wieland ${ }^{3}$

${ }^{1}$ Herz- und Diabetetszentrum NRW, Ruhr University Bochum , Bad Oeynhausen

2 Practice Clinic Heart and Vessels, Dresden

${ }^{3}$ Asklepios Hospital St. Georg, Hamburg

\title{
Diabetes and the heart
}

\section{From guidelines to individualized care}

It was 10 years ago that the process of convergence between vascular and metabolic medicine was addressed in the first issue of the journal Herz dedicated to the topic "Diabetes and the Heart" in 2004. Now, with the fifth edition on this subject, significant progress has been made through the updated joint guidelines of the European Society of Cardiology (ESC) and the European Association for the Study of Diabetes (EASD) dedicated to "Diabetes, Pre-Diabetes and Cardiovascular Diseases.” In 2007 we called it a major breakthrough that both societies came up with joint guidelines emphasizing both the metabolic and the vascular needs of diabetes patients with heart problems. Although much appreciated, these were definitely the least followed guidelines ever. The translation from scientific-based decision making into clinical routine was hardly possible under real-life conditions, as far as diagnostic or therapeutic dimensions were concerned. It took another 6 years to produce the first update, which was recently released during the annual ESC Meeting in Amsterdam. The core investigational algorithm outlining the "principles for diagnosis and management of cardiovascular disease in diabetes mellitus patients with the primary diagnosis of diabetes or a primary diagnosis of cardiovascular disease" remained almost the same, but 11 robust recommendations were added. These comprise pathophysiological considerations, early diagnosis, prevention, risk assessment, risk factor management, lifestyle intervention, preventative target values (blood pressure below 140/85 mmHg,
LDL cholesterol below $1.8 \mathrm{mmol}, \mathrm{HbA}_{\mathrm{lc}}$ below 7\%), multifactorial medical management, revascularization options, heart failure treatment, and, finally, multidisciplinary strategies involving medical subspecialties along with nurses, dieticians, podiatrists, physical therapists, and other health-care professionals. It is particularly valuable that, among others, management of arrhythmias, predominantly atrial fibrillation, is included in the cardiovascular disease continuum of patients with diabetes mellitus. Apparently, the scientific evidence-based guidelines are converted into a multidisciplinary translational document with the primary goal of changing care processes and of overcoming resistance lines forming a multiprofessional alliance for the patient's well-being.

However, most strikingly, major gaps in evidence were explicitly highlighted addressing the questions of clinical relevance that are presently not resolvable on the basis of the available evidence. Therefore, the recent guideline update contributes in three ways by: (1) calling for evidence-based clinical decision making, (2) indicating unmet needs for translation into clinical practice, and (3) asking for additional studies on the remaining questions around the heart in patients with diabetes.

This was the rationale for another issue of Herz on this topic, contributing more advanced reflections: Dirk MüllerWieland discusses the standards of lipid therapy in patients with diabetes and heart disease on the edge between target value achievement and risk-stratified statin therapy. Carsten Tschöpe focus- 
es on congestive heart failure in view of cardiovascular autonomic neuropathypossibly a coupled condition. Markolf Hanefeld works out the risk of malignant arrhythmias and hypoglycemia based on his own original data involving both continuous glucose and Holter ECG measurements. Thomas Meinertz updates the data on atrial fibrillation and diabetes with the recent atrial fibrillation competence network registry. Felix Mahfoud and Sebastian Ewen review the interventional possibilities for hypertension control and the pleiotropic effects on hemodynamics and glucose metabolism. Rolf Dörr comments on the evergreen of individualized decision making between coronary artery bypass grafting over percutaneous coronary intervention on the basis of the prospective FREEDOM trial adding to the SYNTAX strategy of procedural stratification based on the underlying cardiovascular morphology.

This spectrum of scientific clinical contributions demonstrates the vitality of research with the background of open questions and competing solutions in the field that develops as a continuing and extending knowledge platform for physicians and their patients with diabetes and heart problems. The heterogeneous body of evidence and the contradictory incoming trial data seem to confirm our earlier conclusion that appropriate care for these complex patients requires an individualized rather than a generalized approach and this involves drug therapy, medical procedures, and care algorithms.

\section{Corresponding address}

\section{Tschöpe}

Herz- und Diabetetszentrum NRW,

Ruhr University Bochum

Georgstraße 11,

32545 Bad Oeynhausen

Germany

diethelm.tschoepe@ruhr-uni-bochum.de

\section{Compliance with ethical guidelines}

Conflict of interest. D. Tschöpe, R. Dörr, and

D. Müller-Wieland state that there are no conflicts of interest.

\section{Arteriosklerose-Artikel online frei zugänglich}

Hierzulande ist Arteriosklerose eine der häufigsten Gefäßerkrankungen; $18 \%$ der Frauen und 28\% der Männer in der Altersgruppe über 65 Jahre sind betroffen. Im Zuge der ACTION (Arteriosklerose -

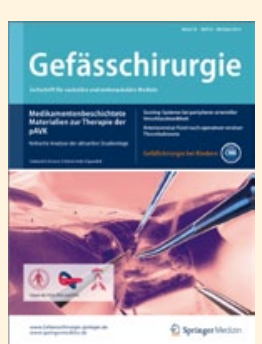

Circulation und

Training InformatiOns Netzwerk)Kampagne der Deutschen Gesellschaft für Gefäßchirurgie und Gefäßmedizin (DGG) stehen zwei

Übersichtsarbeiten zu Arteriosklerose für einen breiten Leserkreis online frei zugänglich bereit.

Im ersten Beitrag in Ausgabe 6/13 von Gefässchirurgie beschreiben die Autoren Risikofaktoren, Epidemiologie und die Ursachen von Arteriosklerose, im zweiten Beitrag in Ausgabe 7/13 von Gefässchirurgie erläutern sie die Manifestation der Arteriosklerose und die Bedeutung von Präventionsmaßnahmen.

Ursachen und Risikofaktoren der Arteriosklerose

dx.doi.org/10.1007/s00772-013-1233-6

Manifestation und Prävention der Arteriosklerose dx.doi.org/10.1007/s00772-013-1235-4

Mit der ACTION -Kampagne trägt die Deutsche Gesellschaft für Gefäßchirurgie und Gefäßmedizin (DGG) zur Aufklärung, Information und Prävention über Arteriosklerose bei.

Suchen Sie noch mehr zum Thema? Mit e.Med, dem Online-Paket von Springer Medizin, können Sie schnell und komfortabel in über 500 medizinischen Fachzeitschriften recherchieren.

Weitere Infos unter: springermedizin.de/eMed. 